\title{
The Design of Switched Reluctance Motor Torque Optimization Controller
}

\author{
Xudong Gao ${ }^{1,2}$, Xudong Wang ${ }^{1}$, Zhongyu Li $^{1}$, Yongqin Zhou ${ }^{1}$ \\ 1. Harbin University of Science and Technology, Harbin, 150080, P.R. China \\ 2. Heilongjiang Institute of Technology, Harbin, 150050, P.R. China \\ gaoxd1973@163.com
}

\begin{abstract}
Switched reluctance motor drive system has greatly practical value in electric vehicle applications. For the characteristics of switched reluctance motor and electric vehicle application requirements, how to reduce the torque ripple effectively and ensure its average output torque, all these become a hot spot of research. Based on this, first of all, the nonlinear model of switched reluctance motor is established and then the function relation between optimal turn-off angle and rotational speed is established based on the dynamic model simulation data, in the end, the optimization torque controller is designed successfully based on variable turn-off angle strategies. The simulation results show that the optimization torque controller can effectively restrain the torque ripple and improve its average torque and realize the torque dynamic characteristics optimization of switch reluctance motor, all these advantages meet the operation performance requirements of electric vehicle.
\end{abstract}

Keywords: switched reluctance motor; torque controller; turn-off angle; dynamic characteristics

\section{Introduction}

With the aggravation of the world's energy crisis and environmental problems, the development and the research of key technologies of new energy vehicles have been paid much attention. The development of new energy vehicles is both the world's automotive industry development goals, and an important task of our country's 12th five-year plan. as a core component of electric vehicles, vehicle driving and matching characteristics of drive motor have become one of the key technologies which urgently need to be researched in the field [1-2]. Switched Reluctance Drive, with its particular advantages, has become the most competitive kind of drivers in contemporary drive motors of new energy vehicles.

Although the switched reluctance motor drive system has a simple structure, low cost, high reliability, superior performance, etc., making it one of the optimal scheme of the electric vehicles' drive system. However, high torque ripple of switched reluctance motor is very harmful to motor itself and actuator of electrical vehicle. Therefore, in the electric vehicle drive system, to reduce the ripple of switched reluctance motor and increase the average torque are crucial to electric vehicle traction characteristics to obtain [2-4].

At present, switch reluctance machine torque control methods which are commonly used includes: optimization control aiming at the opening angle $\theta$ on and off angle $\theta$ off, such as: current double amplitude chopping control [5]; SRM angle optimization control [6]; taking the torque distribution strategy to optimize control, such as: designing the controller based on the torque distribution strategy, obtaining expected torque for each phase, and then through combining the each phase torque to get constant torque, so as to realize the effective suppression of the torque ripple [7]; making the minimum torque error as the optimizing goal, using flux as optimization variables, the optimization is 
analyzed by discretization method, the torque error minimization problem can be converted into mathematical programming problem [8]. The optimized control is based on variable structure control, such as: using fuzzy neural network to carry out offline study to static torque characteristics of SRM inverse model, after the study, on the basis of the torque distribution function, through the real-time online optimization to get phase current waveform which is the expected torque need, equivalent sliding mode variable structure control theory is introduced at the same time, to design the SRM current controller [9].

Some methods, that is intelligent control strategy based on modern control theory, such as fuzzy control [10-11]; sliding mode control [12]; neural network control [13-15], and so on, played a very good effect to a certain extent, promote the development of the switched reluctance motor control technology.

Considering the actual operation performance requirements of the electric vehicles, it is a must to design the torque optimization controller for switched reluctance motor for electric motor, in order to achieve the purpose of reducing the ripple and improving the average torque. This article is based on this. First, it conducts the nonlinear modeling for switched reluctance motor, and then establishes the function relationship of optimal cutoff angle and rotating speed according to the data which are obtained by dynamic model simulation, and finally it completes the design of torque optimization controller based on the strategy of variable turn-off angle. The simulation results show that the optimization torque controller can effectively restrain the torque ripple and improve its average torque. So it implements the dynamic characteristics optimization of switched reluctance motor torque, to meet the performance requirements in the process of the electric car run.

\section{The Nonlinear Model of SRM}

Switched reluctance motor has highly nonlinear characteristics, only accurate nonlinear modeling for switched reluctance motor can accurately analyze parameter performances and its dynamic characteristics. Scholars at home and abroad based on switched reluctance motor model proposed many methods, such as function-analysis method [16], neural-network method [17], experimental method or finite element analysis method [1819]. As shown in Figure 1: A typical switched reluctance motor drive system consists of four parts: SR motors, power converters, controllers and detectors.

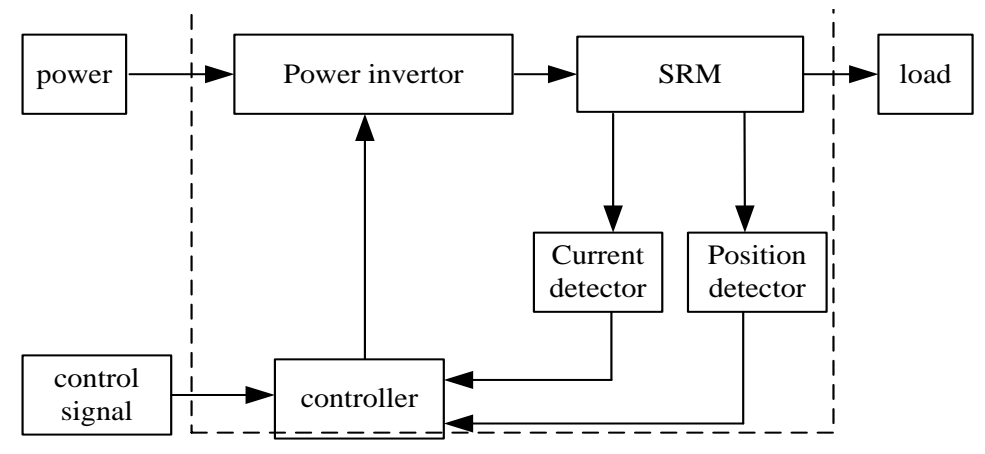

Figure 1. The Structure Diagram of SRD System

Because the current of each phase winding of the main circuit of asymmetrical halfbridge type can be independently controlled, and during the commutation, the appropriate superposition through the current of each phase can achieve a control of the torque ripple; meanwhile, the main circuit of this structure can put the magnetic energy storage in the form of electrical energy back to the power supply, it improves energy efficiency and increases the mileage of electric cars. Based on the above considerations, opt for main circuit of asymmetrical half-bridge power converter. 


\subsection{The Basic Equations of SRM}

According to the analysis of each phase circuit, the flux linkage of each phase $\psi_{k}$ can be get by calculating the integral of the difference between each phase voltage $u_{k}$ and each winding voltage drop $R_{k} i_{k}$ :

$$
\psi_{k}(i, \theta)=\int\left(u_{k}-R_{k} i_{k}\right) d t
$$

In the formula: $\psi_{k}$ is the NO.k phase flux linkage; $u_{k}$ is the NO.k phase voltage across the winding; $i_{k}$ is the NO.k phase branch current; $\theta$ is the rotor angle.

According to the principle of magnetic co energy, by analyzing the flux characteristic, electromagnetic torque can be calculated based on the phase current and rotor position angle measured:

$$
T_{e}(i, \theta)=\frac{\partial}{\partial \theta} W^{\prime}(i, \theta)=\frac{\partial}{\partial \theta} \int_{0}^{i} \psi(i, \theta) d i
$$

In the formula: $T_{e}$ is electromagnetic torque; $W^{\prime}(i, \theta)$ is magnetic co energy.

According to the principle of mechanics, the mechanical motion equation of SRM can be getting:

$$
T_{e}(i, \theta)=J \frac{d \omega}{d t}+B \omega+T_{L}
$$

In the formula: $J$ is the inertia of rotation; $B$ is the coefficient of friction; $\omega$ is the rotor angular velocity; $T_{L}$ is the load torque.

The average torque is very important for the performance of switched reluctance motor drive system. In this paper, the type of the researched switched reluctance motor is four phase $8 / 6$ pole structure; its average output torque $T_{a}$ is calculated as follows:

$$
T_{a}=\frac{12}{\pi} \int_{0}^{\pi / 3} T_{e}(i, \theta) d \theta
$$

Leading to the weakened stationary and comfort of electric vehicle, the torque ripple and noise of SRM are the obvious defects; consequently, the research on SRM is important and valuable. The torque ripple coefficient of SRM is calculated as follows:

$$
T_{r}=\frac{T_{\max }-T_{\min }}{T_{a}}
$$

In the formula: $T_{r}$ is the torque ripple coefficient ; $T_{\max }$ is the maximum value of electromagnetic torque; $T_{\min }$ is the minimum value of electromagnetic torque; $T_{a}$ is the average output torque.

\subsection{The Characteristics of Flux Linkage and Electromagnetic Torque}

How to establish the flux linkage and phase current, position angle function $\psi(i, \theta)$ is the necessary premise of accurately establishing a simulation model of switched reluctance motor. Before the establishment of switched reluctance motor nonlinear model, first you need to establish a function of flux linkage and the phase current, position angle $\psi(i, \theta)$.

The research process of this paper as follows: first of all, getting flux linkage values $\psi(i, \theta)$, through the inverse function operation on flux values and position angles, the corresponding current values is calculated. Then using two-dimensional curved surface interpolation method to establish $i(\psi, \theta)$, it is a function relationship between the phase current and flux linkage, position angle. 
Function relationship $i(\psi, \theta)$ can reflect the flux change rule and the saturation characteristic of the machine. On the premise of known phase current and position angle, using the formula (2), the motor corresponding electromagnetic torque can be obtained by calculating, and help to establish a function of electromagnetic torque and the phase current, position angle $T(i, \theta)$.

As shown in Figure 2, in this paper, the $T(i, \theta)$ is separately calculated, and establish $3 \mathrm{~d}$ look-up table module of the electromagnetic torque, phase current and position angle in the Simulink environment, with the phase current and position angle as input, to obtain the corresponding electromagnetic torque characteristic curve.

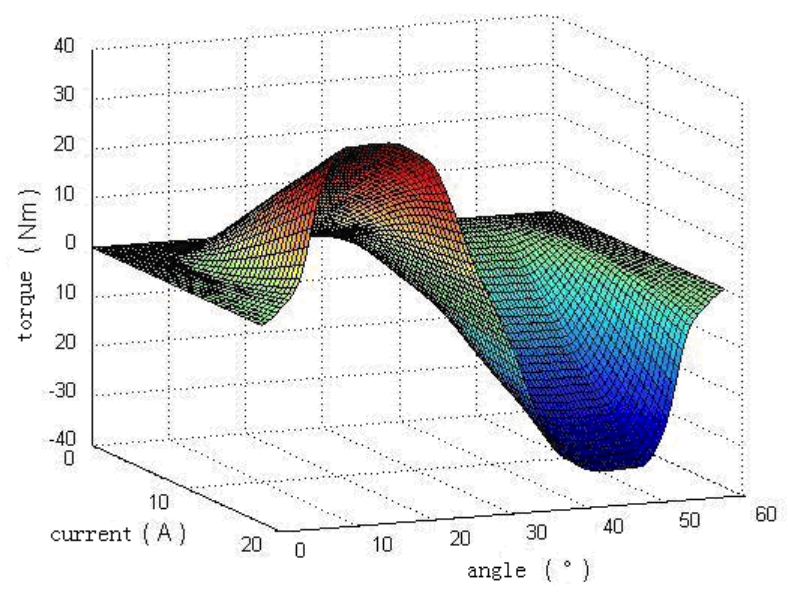

Figure 2. The Electromagnetic Torque Characteristics of SRM

\subsection{The Nonlinear Dynamic Model of SRM}

According to the formula (1) of the flux $\psi_{k}$, the value of the flux in each phase is obtained by integrating of the difference between the phase voltage and the voltage drop across the windings, then through the above description establish the function relationship between the phase current and the electromagnetic torque, finally, obtain the each phase current and electromagnetic torque. As shown in Figure 3, in MATLAB / Simulink environment to establish the switched reluctance motor model.

According to the four-phase asymmetrical half-bridge-type, establish power converter module for switched reluctance motor, by the formula (3) establish the mechanical motion module, the angle generation module, current chopping control module and switch control module. In MATLAB to construct the dynamic model of the switched reluctance motor drive system.

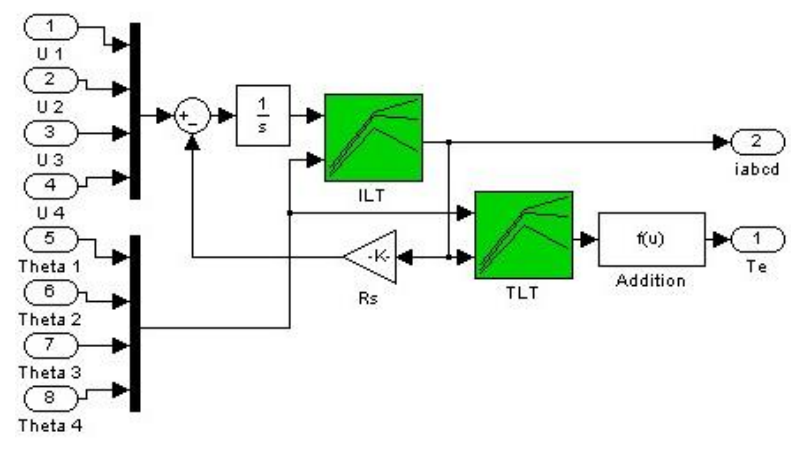

Figure 3. The Model of Switched Reluctance Motor 


\section{The Simulation of Drive System of SRM}

The performance parameters of $5 \mathrm{~kW}$ four-phase $8 / 6$ pole switched reluctance motor of this study are: the rated voltage $\mathrm{U}=140 \mathrm{~V}$, the reference current $I_{\text {ref }}=10 \mathrm{~A}$, the phase winding resistance $\mathrm{R}=1.26 \Omega$, friction coefficient $\mathrm{B}=0.0179$, the system inertia $J=$ $0.0015 \mathrm{~kg} . \mathrm{m} 2$, rated speed $\mathrm{n}=3000 \mathrm{r} / \mathrm{min}$.

The change of turn-off angle of switched reluctance motor has a great impact on its torque and torque ripple, so researching torque and torque ripple under different turn-off angle has very important significance to improve the dynamic characteristics of switched reluctance motor.

This article sets the turn-on angle $\alpha=0^{\circ}$, the reference current $I_{\text {ref }}=10 \mathrm{~A}$, under this precondition, through rationally regulating turn-off angle and output speed, and simulating for torque characteristics of switched reluctance motor(Speed output range is $0-3200 \mathrm{r} / \mathrm{min}$; the adjustment range of turn-off angle $\theta$ off is $21.5^{\circ}-33.5^{\circ}$ ), get the function relationship between torque and turn-off angle, output speed, and the function relationship between the torque ripple and the turn-off angle, the output speed, finally establish the torque optimized controller and achieve the goal of optimal torque and torque ripple.

At a given speed and turn-off angle adjustment range, and by simulation for torque characteristics of switched reluctance motor, we can get the motor torque characteristics under different conditions of speed and turn-off angle, including the average torque characteristics and torque ripple characteristics.

As shown in Figure 4, in order to visually see the function relationship between torque ripple and speed, turn-off angle, we will make the simulation data into the three dimensional surfaces form, and analysis of the data shows that: in the range of 0-2400 r/min, the torque ripple factor $T_{r}$ decreases with increasing speed; in the range of 2400$3200 \mathrm{r} / \mathrm{min}$, the torque ripple factor $T_{r}$ increases with increasing speed. Data were obtained through the simulation, we can get under the condition of each rotating speed that, the turn-off angle of fluctuation coefficient reaches the minimum value, thus to establish the function relationship $\theta_{o p}=f(\omega)$ between turn-off angle and speed, to realize the optimization of torque controller. Figure 5 is a three-dimensional surface of function relationship between torque and speed, the turn-off angle, we can see that, under the same speed conditions, different turn-off angle $\theta_{\text {off }}$ have little effect on the torque output.

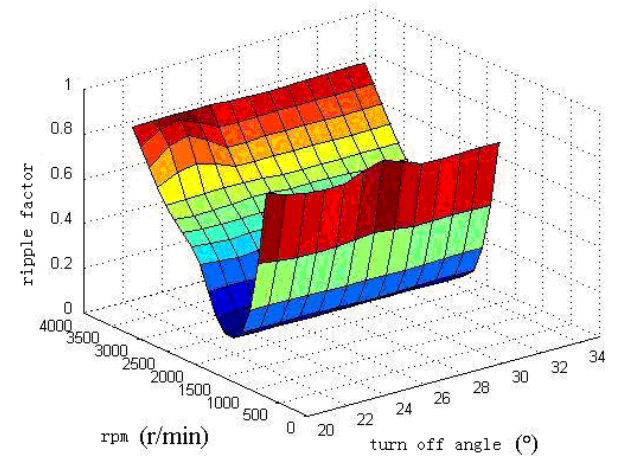

Figure 4. The Characteristic Curve of Torque Ripple, Speed and Turn-off Angle 


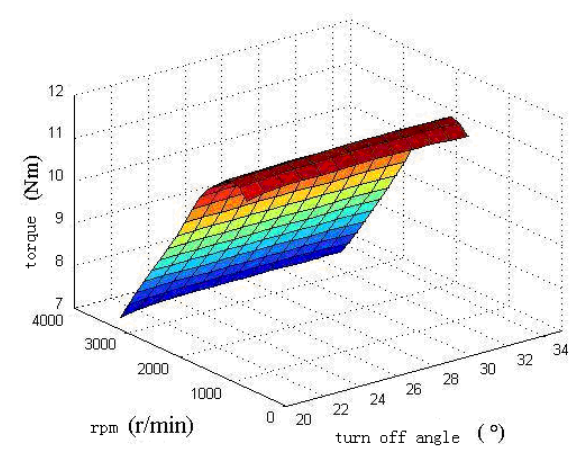

Figure 5. The Characteristic Curve of Torque, Speed and Turn-off Angle

\section{Torque Optimization Controller Design}

The choice of switched reluctance motor turn-off angle $\theta_{\text {off }}$ will directly affect the size of the average torque and torque ripple. How to dynamically adjust the size of the turn-off angle in order to realize the improvement of the comprehensive performance of the switched reluctance motor drive system become the key problem which must be considered.

In this paper, according to the established the function relationship between torque ripple and speed and turn-off angle, and the function relationship between torque and rotational speed and turn-off angle, meanwhile, under the condition of same rotor speed, considering two factors, pulsation coefficient and average torque motor, and based on the premise of not to reduce the motor average torque, making reducing the motor pulsation coefficient as the goal, selecting the optimal cut-off angle $\theta_{\text {off }}$ matched the speed, so as to establish the function relation between the optimal cut-off angle and the rotational speeds. This paper gets a fitted curve $\theta_{o p}=f(\omega)$ by simulation data.

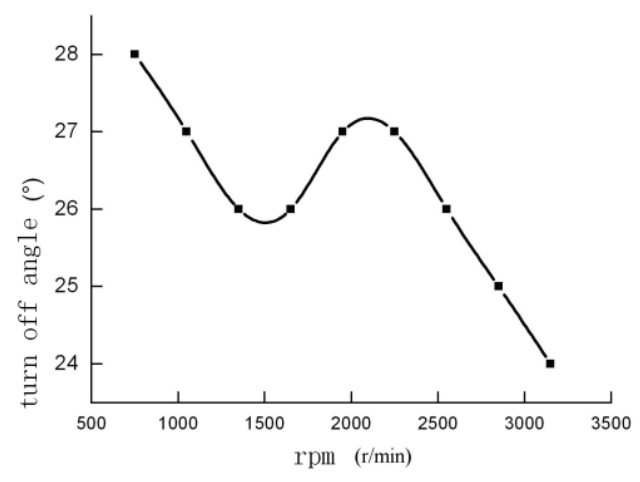

Figure 6. The Characteristic Curve of the Optimum Turn-off Angle and
Speed

Using the optimal turn-off angle and speed relation curve $\theta_{o p}=f(\omega)$, variable turn-off Angle model is set up, implementing the optimization of switch reluctance motor torque ripple and the average torque. Through the Simulink environment and one-dimensional look-up table modules, the established model of variable turn-off angle to import switched reluctance motor used in electric vehicle simulation platform. This article introduces the manual switch module to realize the quick switch between variable turn-off angle and fixed turn-off angle of switch reluctance motor model, in order to comparison and analysis of simulation results. 


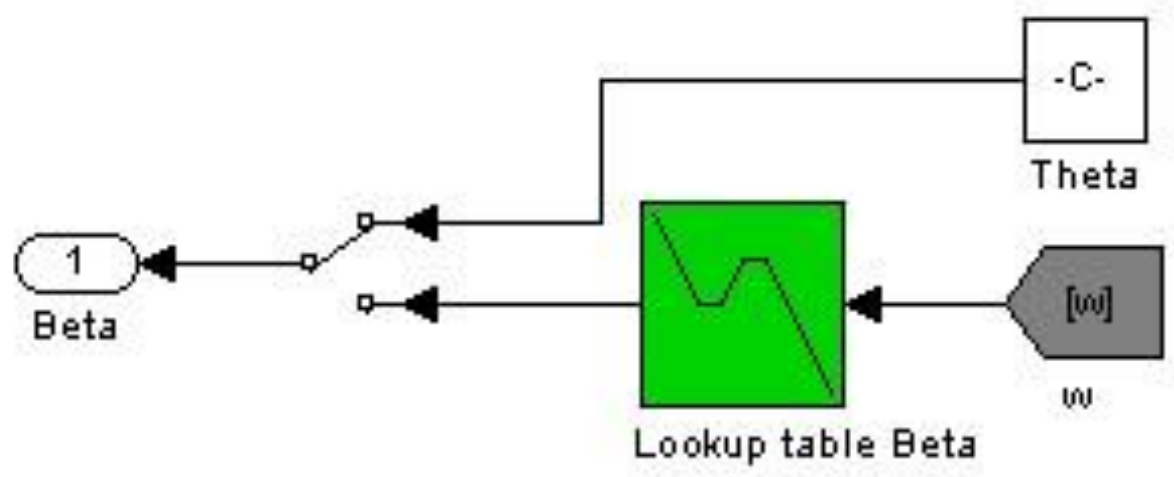

Figure 7. The Simulation of the Variable Turn-off Angle Model

\section{The Simulation Results and Contrast}

According to the nonlinear dynamic model of switched reluctance motor, based on the simulation in MATLAB/Simulink, the switched reluctance motor which is selected is simulated. The fixed turn-off angle and the variable turn-off angle are respectively selected as the turn-off angle in the paper, the voltage $\mathrm{U}=140 \mathrm{~V}$; reference current $I_{\text {ref }}=$ $10 \mathrm{~A}$; the turn-on angle $\alpha=0^{\circ}$; fixed off-angle $\theta=22.5^{\circ}$.

Through giving the motor a steady speed, you can respectively get the before and after optimization torque ripple coefficient value under this speed conditions, which will be conducted before and after optimization controller comparison. Figure 8 is a given speed $2500 \mathrm{r} / \mathrm{min}$ before and after optimization synthesis torque comparison chart. As can be seen after observation, the optimized motor torque ripple has improved; its average output torque obtains a certain improvement, so it achieves the purpose of performance optimization of switched reluctance motor drive system.

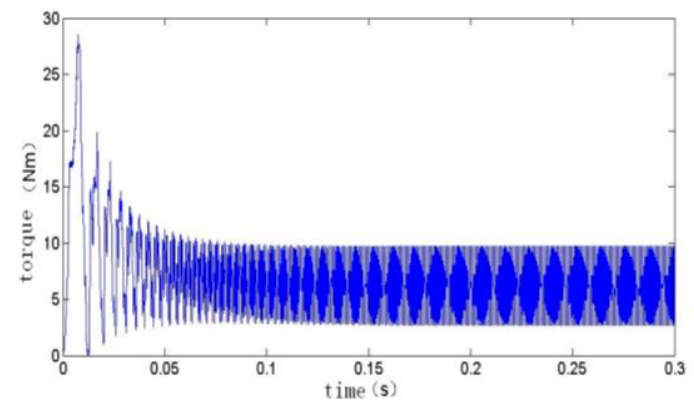

(a) Before optimization

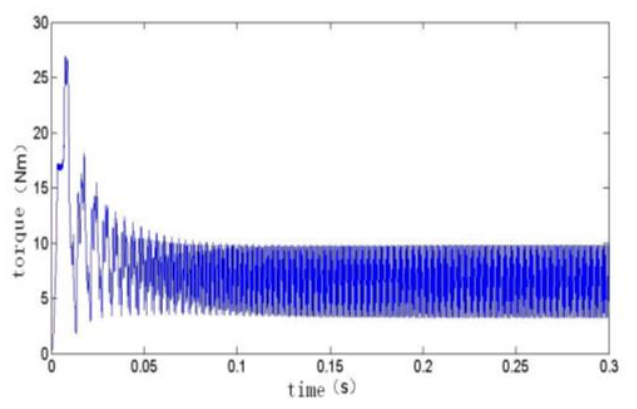

(b) After optimization

Figure 8. The Synthesis of Torque at the Speed of $2500 \mathrm{r} / \mathrm{min}$

As shown in Figure 9 (a), this article will get a curve comparison (the black square curve is the before optimization curve, the red circular curve is the after optimization curve) obtained by the before and after the optimization torque ripple coefficient of switched reluctance motor under the different speed conditions. By the curve comparison can be seen that the optimization torque controller designed in this paper realizes the effective suppression to the torque ripple. It can also be seen that when switched reluctance motor is in low speed and high speed range, the optimization torque controller has a most obvious effect on reducing torque ripple coefficient, which further prove its effectiveness.

Under the premise of not reducing the average torque as much as possible, to reduce the torque ripple is the goal of optimizing the controller, as shown in Figure 9 (b), this 
article will put the average torque data of the before and after optimization obtained in the different speed conditions into the curve (the black square curve is the before optimization curve, the red circular curve is the after optimization curve).

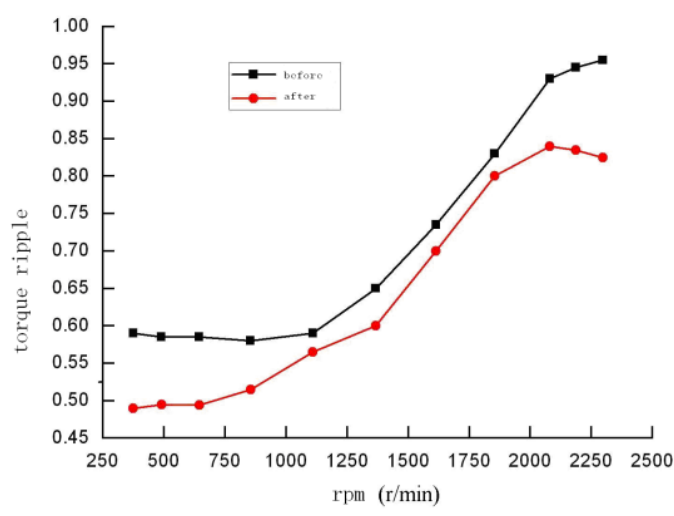

(a) The contrast of torque ripple coefficient

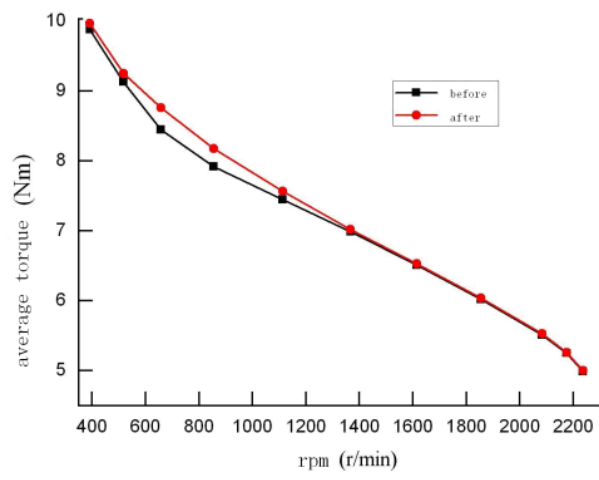

(b) The contrast of the average torque

Figure 9. The Contrast of the Torque Ripple Coefficient and Average Torque before and after Optimization

By the curve comparison can be seen that the optimization torque controller designed in the paper realizes the improvement of the average torque, especially in the speed at 550 $\mathrm{r} / \mathrm{min}$ to $1350 \mathrm{r} / \mathrm{min}$ range, the average output torque obtains obvious improvement.

The optimization torque controller designed in this paper can effectively restrain the torque ripple of switched reluctance motor in low speed and high speed zone, while it also has some inhibitory effect on the medium-speed pulsation, at the same time it reduces the motor torque ripple, and it can also make the average output torque get some improvement, so it achieves the double index optimization of reducing torque ripple and improving the average torque, and in the field of electric vehicle technology research it has certain practical value.

\section{Conclusions}

This paper establishes its nonlinear dynamic simulation model, which is based on the flux characteristics of $5 \mathrm{Kw}$ four phase $8 / 6$ pole switch reluctance machine used in electric cars, and put forward a kind of torque optimization control method based on variable turn-off angle control strategy. Based on the flux characteristics of switched reluctance motor, its nonlinear dynamic simulation model is established. Through simulation to dynamic model, this paper established the function relation of the motor torque ripple, the average torque and rotational speed, shut-off angle. Aimed at reducing the torque ripple and improving the average torque, through selecting optimal turn-off angle which is under the series rotate speed to establish the function relationship between the optimal cut-off angles and rotate speed, and complete the further design of the torque optimization controller which is based on variable turn-off angle.

By analyzing the simulation results, the optimization torque controller designed in this paper can effectively reduce the torque ripple and improve the average output torque, achieving the double index optimization of torque ripple and the average torque, reaching the purpose of torque dynamic characteristic optimization of the switched reluctance motor. In the fields of the electric vehicle applications, it has a certain theoretical study and practical application value. 


\section{References}

[1] J.-h. Wu, "Design and application of switched reluctance motor [M]", Beijing: Machinery Industry Press, (2000).

[2] H.-x. Wu, "Switch reluctance motor theory and control technology [M]", Beijing: Chinese Power Press, (2010).

[3] Q.-h. Zhan, "Switched reluctance motor [M]", Wuhan: Huazhong University of Science and Technology Press, (1992).

[4] N Inanc and V. Ozbulur, "Torque ripple minimization of a switched reluctance motor by using continuous sliding mode control technique [J]”, Electric Power Systems Research, vol. 66, no. 3, (2003), pp. 241-251.

[5] H.-d. Wang, X.-1. Wang and Y. Wang, "Switched reluctance motor current double amplitude choppingWave control [J]", Proceedings of the CSEE, vol. 20, no. 4, (2000), pp. 83-86.

[6] L. Chen, Y.-x. Huang and X. Chen, "Control optimization of neural network based on the perspective of SRM Business strategy research of [J]", Electric drive, vol. 41, no. 3, (2011), pp. 46-50.

[7] Z.-1. Shi, Y.-s. Huang and X. Chen, "Research on control system of Switched Reluctance Motor Based on torque distribution strategy [J]", Coal mine machinery, (2010).

[8] J.-y. Cao, Z.-d. Zhuo and Y.-p. Chen, "A new method of switch reluctance motor torque control [J]", Proceedings of the CSEE, vol. 25, no. 6, (2005), pp. 88-94.

[9] H.-t. ZHENG and J.-p. JIANG, "Switched reluctance motor high performance torque control strategy research [J]", Transactions of China Electrothchnical Society, vol. 9, (2005), pp. 25-28.

[10] L. O. A. P. Henriques, L. G. B. Rolim and Walter. I. Suemit su, "Torque Ripple Minimization in a Switched Reluctance Drive by Neuro-fuzzy Compensation [J]", IEEE Transactions on magnetics, vol. 36, no. 5, (2000), pp. 3592-3594.

[11] D.-1. Liang, W. Ding and Z.-m. Yu, "Modeling for Switched Reluctance Motor Based on adaptive network based fuzzy inference system [J]", Proceedings of the CSEE, vol. 28, no. 9, (2008), pp. 86-92.

[12] A. M. Roy, S. I. Mohammad and H. Iqbal, "Application of a Sliding Mode Observer for Position and Speed Estimation in Switched Reluctance Motor Drives [J]", IEEE Transactions on Industry Applications, vol. 37, no. 1, (2001), pp. 51-58.

[13] J. G. O' Donavan, P. J. Roche and R. C. Kavanagh, "Neural Network Based Torque Ripple Minimization in a Switched Reluctance Motor [J]", IECON, (1994), pp. 1226-1231.

[14] C.-1. Xia and J. Xiu, "Switched reluctance motor adaptive PID prediction model of nonlinear control based on RBF neural network [J]", Proceedings of the CSEE, vol. 27, no. 3, (2007), pp. 57-61.

[15] D S. Reay, T C. Green and B W. Williams, "Application of Associative Memory Neural Networks to the Control of a Switched Reluctance Motor [J]", IECON, vol. 1, (1993), pp. 200-206.

[16] W. Ding and D.-1. Liang, "A switched reluctance motor nonlinear flux linkage and torque modeling method [J]", Electric Machines and Control, vol. 12, no. 6, (2008), pp. 659-665.

[17] L.-y. Si, H. Lin and Z. Liu, "Modeling of Switched Reluctance Motor Based on least squares phasor machine [J]", Proceedings of the CSEE, vol. 27, no. 6, (2007), pp. 26-30.

[18] H.-t. Zheng, J.-1. Cai and J.-p. Jiang, "A nonlinear model of Switched Reluctance Motor Based on variable structure fuzzy neural network [J]", Transactions of China Electrothchnical Society, vol. 16, no. 6, (2001), pp. 1-6.

[19] X. D. Xue, K W E Cheng, and S L Ho, "A Position Stepping Method for Predicting Performances of Switched Reluctance Motor Drive [J]", IEEE Transactions on Energy Conversation, vol. 22, no. 4, (2007), pp. 839-847. 
International Journal of Control and Automation Vol.8, No.5 (2015) 